\title{
Localised Gingival Overgrowth in Patient taking Amlodipine
}

\author{
Dr. Arjun Hari Rijal, ${ }^{1}$ Dr. Bhageshwar Dhami, ${ }^{1}$ Dr. Nashib Pandey, ${ }^{1}$ \\ Dr. Deepa Aryal, ${ }^{1}$ Dr. Kamana Neupane ${ }^{1}$ \\ ${ }^{1}$ Department of Periodontology and Oral Implantology, \\ Kantipur Dental College Teaching Hospital and Research Centre, Kathmandu, Nepal.
}

\begin{abstract}
Gingival enlargement is an increase in the size of gingiva. It is one of the side effects of systemic administration of antihypertensives, anticonvulsants, and immunosuppressants. Amlodipine, a new third-generation dihydropyridine, very useful in middle-aged to older aged patients for various cardiovascular conditions can cause gingival enlargement. Treatment modalities for drug induced gingival enlargement include removal of local irritating factors, meticulous plaque removal and drug substitution after consultation with a physician. This article reports an amlodipine induced gingival enlargement and its treatment in a 40 years old hypertensive male patient.

Keywords: Amlodipine; gingival enlargement; gingivectomy.
\end{abstract}

\section{INTRODUCTION}

A multifactorial condition of gingiva characterised by an increase in size is called gingival enlargement. ${ }^{1}$ The most common form is drug induced gingival enlargement. ${ }^{2}$ Three groups of drugs can lead to enlargement: anticonvulsants, calcium channel blockers, and immunosuppressants. It was first reported in 1939 with chronic usage of phenytoin. ${ }^{3}$ Calcium channel-blocking (CCBs) agents are used extensively for the management of cardiovascular conditions. ${ }^{4}$ Amongst CCBs, amlodipine, a newest third-generation dihydropyridine agent, is frequently prescribed. These medications require lifelong administration, leading to side effects like gingival overgrowths.

\section{CASE REPORT}

A 40 years old male individual came to the Department of Periodontology and Oral Implantology, Kantipur Dental College Teaching Hospital, and Research Centre, Basundhara, Kathmandu with a chief complaint of localised painless swelling of gingiva in the upper front region of jaw for six months (Figure 1). The patient was on Amlodipine five milligrams two times a day for two years. The swelling was

\footnotetext{
Correspondence:

Dr. Arjun Hari Rijal

Department of Periodontology and Oral Implantology, Kantipur Dental College Teachig Hospital and Research Centre, Kathmandu, Nepal.

email: rajrijal27@gmail.com

Citation

Rijal AH, Dhami B, Pandey N, Aryal D, Neupane K. Localised Gingival Overgrowth in Patient taking Amlodipine. J Nepal Soc Perio Oral Implantol. 2020;4(8):96-9
}

insidious in onset and had enlarged gradually reaching current diameter in the upper front region of the jaw, which was not associated with pain/sensitivity/bleeding or any exudate. On general examination, the patient was moderately built and nourished. Overlying gingiva was red, smooth, slightly erythematous, and non-ulcerated (Figure 1b). Intraoral examination revealed a solitary, solid, nonfluctuant, lobulated, irregular, well-circumscribed, localised gingival enlargement of about one centimetre diameter with inflamed surface with respect to 12,13 , and 14 (teeth numbering according to two-digit numbering system, Figure
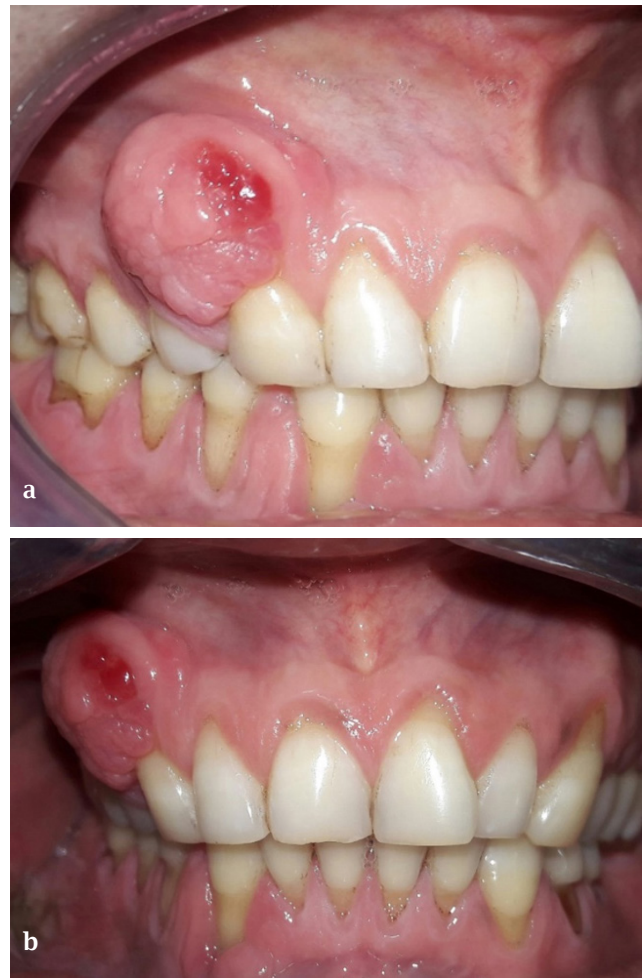

Figure 1: Initial presentation of the lesion. - a. Front View b. Side View 
Table 1: Different phases of treatment.

\begin{tabular}{|l|l|}
\hline \multicolumn{1}{|c|}{ Phases } & \multicolumn{1}{c|}{ Therapy } \\
\hline Initial Phase, 1st week & $\begin{array}{l}\text { History taking, examination, scaling and root planing, chlorhexidine mouth rinse 0.2\% two } \\
\text { times daily (BD) for two weeks, antibiotic coverage for one week. }\end{array}$ \\
\hline 2nd week & Evaluation of phase 1, root planing, and curettage i.r.t. 12,13, and 14 \\
\hline 4th week & Re-evaluation of gingival swelling \\
\hline Surgical phase (5th week) & Surgical excision of gingival mass i.r.t. 12,13, and 14 \\
\hline Maintenance phase & Evaluation, monitoring, and scaling \\
\hline
\end{tabular}

1a). The swelling was pink in colour, firm in consistency, non-tender with no expansion of underlying cortical plate, and showed bleeding on manipulation. Swelling involved marginal, interdental, and attached gingivae and was associated with a pocket of about nine millimetres in respect to (i.r.t.) 13.

Ideally, we have to wait at least six months after the substitution of drugs and before the commencement of the surgical phase. The patient was concerned about the possibility of any cancerous lesion, so he wanted a biopsy of the lesion. That is why one month after nonsurgical therapy, the patient was recalled for a re-evaluation of gingival mass and surgical excision was planned after one week. Bard-Parker knife \#15 was used for surgical excision (Figure 2). Curettage and root planing were done. Periodontal dressing was given after cessation of bleeding. The patient was recalled after one week for periodontal dressing removal and irrigated with normal saline (Figure 5). Then, patient was recalled after two weeks and three months (Figure 5,6). The patient was kept on maintenance phase.

Excised tissue was sent for histopathological examination which revealed hyperplastic parakeratinised stratified squamous epithelium with long rete ridges and areas of pseudoepitheliomatous hyperplasia (Figure 3a). Connective tissue was composed of dense bundles of collagen fibres with areas of chronic inflammatory infiltration chiefly plasma cells (Figure 3b).
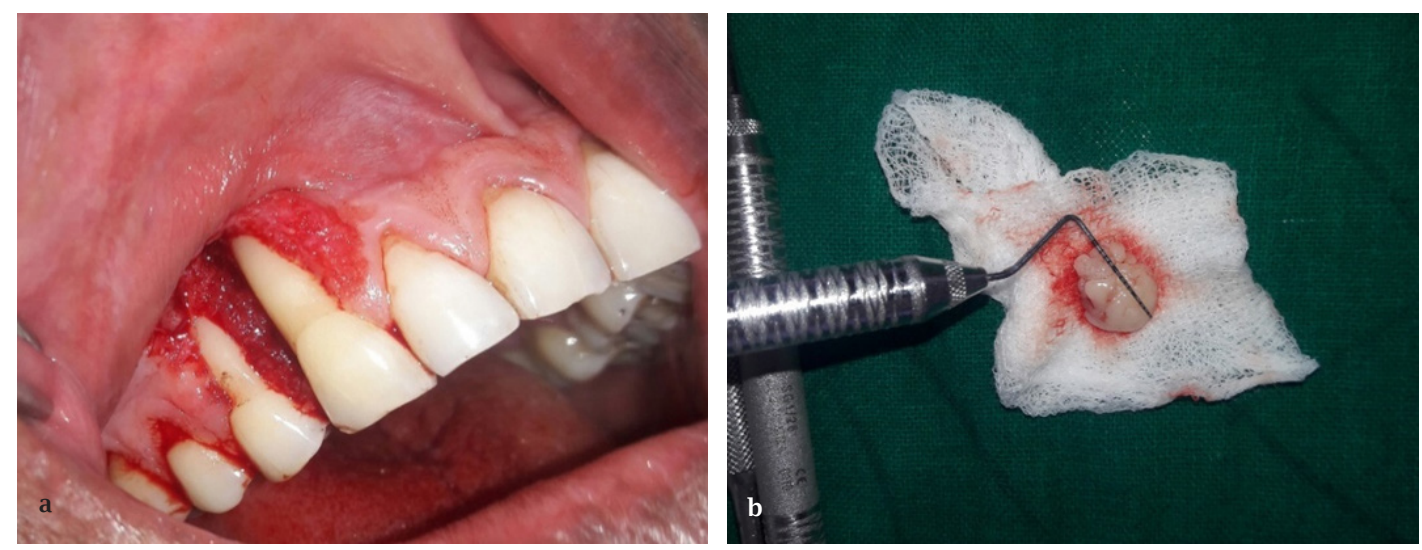

Figure 2: Surgical excision of lesion. - a. Surgical site after excision. b. Measurement of specimen.
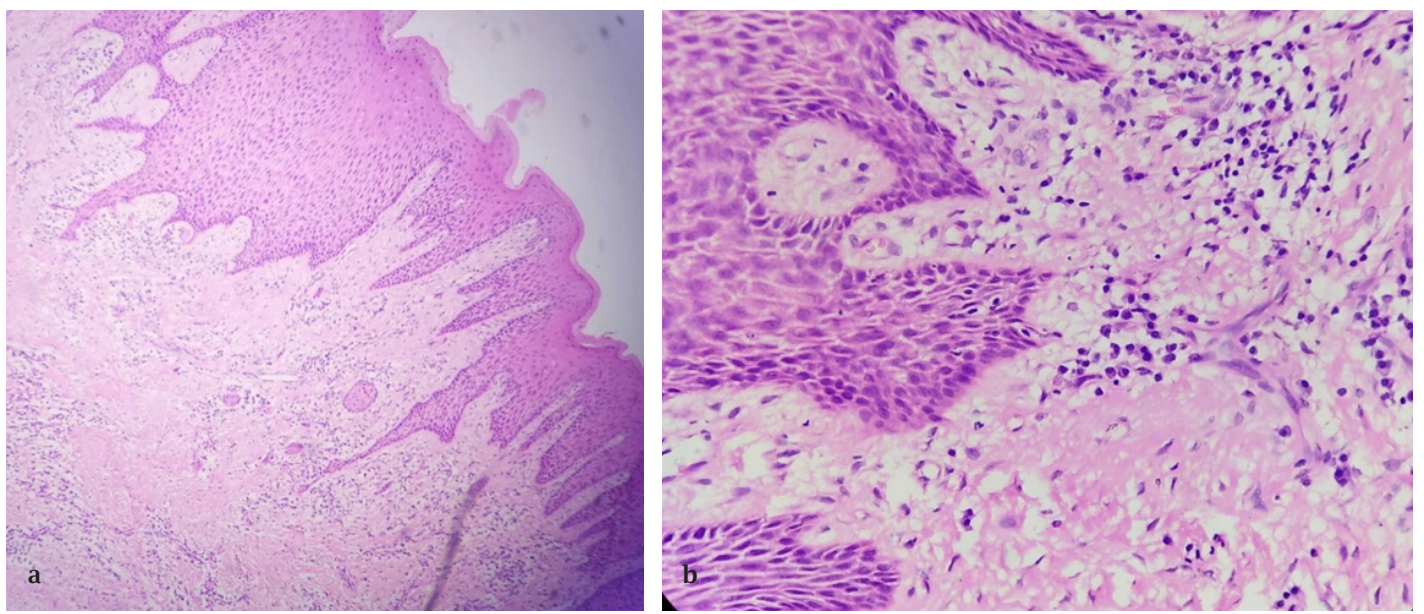

Figure 3: Histologic presentation. - a: Hyperplastic parakeratinised stratified squamous epithelium with long rete ridges. b: Areas of chronic inflammatory infiltration chiefly plasma cells. 


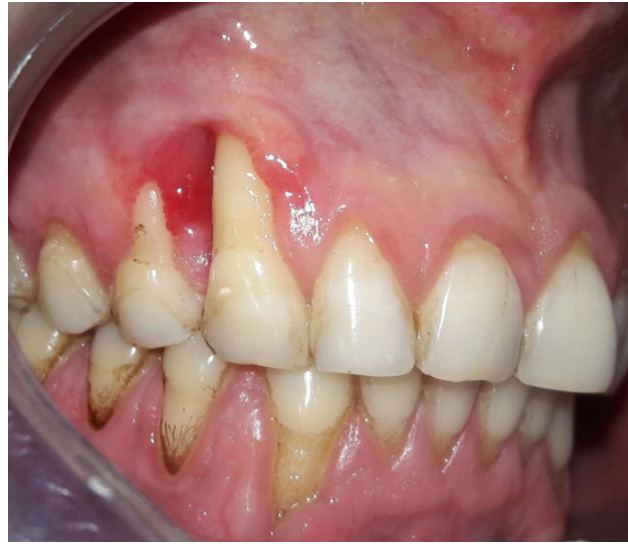

Figure 4: Follow-up at one week.

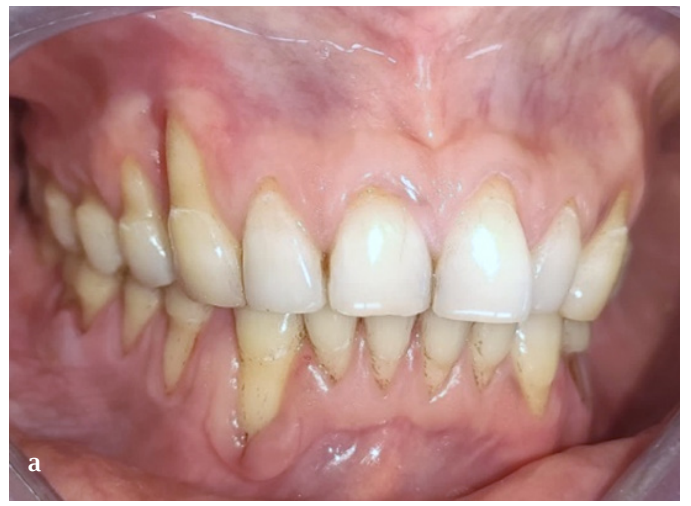

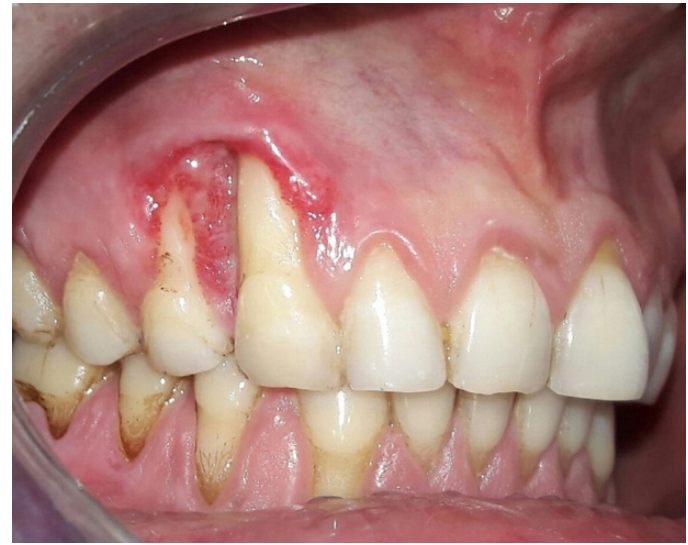

Figure 5: Follow-up at two weeks.

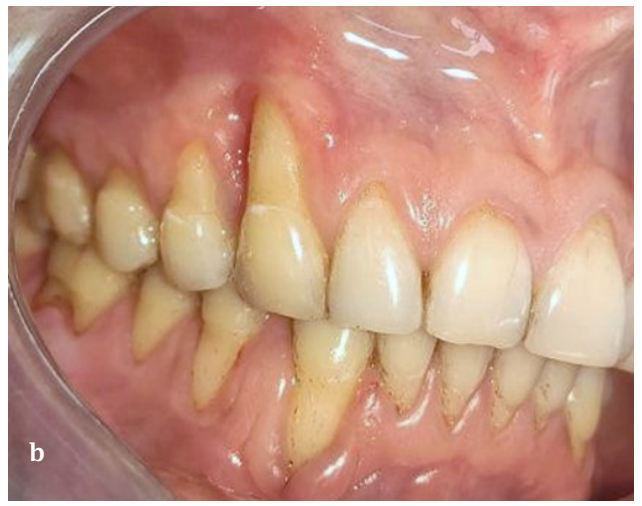

Figure 6: Follow-up at three months. - a. Front View b. Side View

\section{DISCUSSION}

Amlodipine is a third-generation dihydropyridine, useful in middle to older aged patients for various cardiovascular conditions. ${ }^{5}$ Drug-induced gingival overgrowth due to calcium channel blocker may occur due to decrease influx of calcium ions across cell membrane because of reduced membrane permeability. With the decreased calcium influx, the secretory function of affected fibroblasts or collagenases production is reduced/inhibited. Thus, increased fibroblastic proliferation and collagen synthesis occur resulting in an enlargement.

Previously, amlodipine was considered as a "safe drug" when compared to other CCB's for having relatively few side effects. ${ }^{6}$ In the past, the prevalence of amlodipine induced gingival overgrowth was $1.7 \%-3.3 \%$ which may be due to a low prescription rate. 6 Nowadays, these data suggest that there has been an increase in number of these cases.

Amlodipine induced gingival enlargement shows inflammatory feature and has three times more predilection for males than females. ${ }^{7}$ In a study done by Jorgensen et al. on a series of 150 cardiac patients, it was found that, $5 \mathrm{mg} /$ day amlodipine cannot induce gingival hyperplasia even if it is taken for more than six months. ${ }^{8}$ Seymour et al. reported three patients with poor periodontal conditions who developed gingival hyperplasia upon chronic usage (at least three months) of amlodipine. ${ }^{9}$ Above reported patient was under medication, amlodipine for the past two years but patient reported of gingival enlargement only for the past six months.

Drug dosage is a poor predictor of gingival changes. Plasma concentration of calcium channel blockers was identified as a risk factor for severity of the gingival change. ${ }^{10}$ The exact mechanism of drug induced gingival enlargement is unknown, considered as a multifactorial condition resulting from the interaction between drugs with host cellular level.

Treatment modalities include removal of local irritating factors, meticulous plaque removal, and drug substitution after consultation with a physician. The main aim of nonsurgical therapy is to reduce the inflammatory component in gingival tissues and thereby avoid the need for surgery. Even after completion of non-surgical therapy, if there is persistent gingival enlargement, it can be treated with gingivectomy with or without periodontal surgery and in this case, the lesion was excised by gingivectomy. Gingival 
overgrowth causes aesthetic, functional, psychological, and masticatory disturbance of the oral cavity. Complete excision of gingival mass is the treatment of choice which can improve above-stated problems and enable patients to improve plaque control. Patient education and proper oral hygiene maintenance play a vital role in future maintenance.

Conflict of Interest: None.

\section{REFERENCES}

1. Newman MG, Takei H, Klokkevold PR, Carranza FA, editors. Newman and Carranza's Clinical Periodontology. 13th ed. Philadelphia (PA): Saunders, Elsevier; 2018.

2. Agrawal AA. Gingival enlargements: Differential diagnosis and review of literature. World J Clin Cases. 2015 Sep 16;3(9):779-88.

3. Kimball OP. The treatment of epilepsy with sodium diphenyl hydantoinate. J Am Med Assoc. 1939;112(13):1244-5.

4. Harold CE, editor. Physician's drug handbook. 12th ed. Spring House (PA): Lippincott Williams and Wilkins; 2007.

5. Levine CB, Fahrbach KR, Frame D, Connelly JE, Estok RP, Stone LR, et al. Effect of amlodipine on systolic blood pressure. Clin Ther. 2003;25(1):35-57.

6. Tejnani A, Gandevivala A, Bhanushali D, Gourkhede S. Combined treatment for a combined enlargement. J Indian Soc Periodontol. 2014;18(4):516-9.

7. Ellis JS, Seymour RA, Steele JG, Robertson P, Butler TJ, Thomason JM. Prevalence of gingival overgrowth induced by calcium channel blockers: a community-based study. J Periodontol. 1999 Jan;70(1):63-7.

8. Jorgensen MG. Prevalence of amlodipine-related gingival hyperplasia. J Periodontol. 1997;68(7):676-8.

9. Seymour RA, Ellis JS, Thomason JM, Monkman S, Idle JR. Amlodipine induced gingival overgrowth. J Clin Periodontal. 1994;21(4):281-3.

10. Ellis JS, Seymour RA, Monkman SC, Idle JR. Gingival sequestration of nifedipine in nifedipine-induced gingival overgrowth. Lancet. 1992;339(8806):1382-3. 